\title{
Analysis of spatial dynamic of epizootic process of bluetongue and its risk factors
}

\author{
Fayssal Bouchemla ${ }^{1}$, Olga Mikhailovna Popova² and Valerey Alexandrovich Agoltsov ${ }^{1}$
}

1. Department of Animal Disease, Veterinarian and Sanitarian Expertise, Faculty of Veterinary Medicine, Saratov State Agrarian University (N.I. Vavilov), Saratov, Russia; 2. Department of Food Technology, Faculty of Veterinary Medicine, Saratov State Agrarian University (N.I. Vavilov), Saratov, Russia.

Corresponding author: Fayssal Bouchemla, e-mail: faysselj18@yahoo.com

Co-authors: OMP: popova@sgau.ru, VAA: agoltsov-saratov@yandex.ru

Received: 19-06-2017, Accepted: 08-09-2017, Published online: 04-10-2017

doi: 10.14202/vetworld.2017.1173-1183 How to cite this article: Bouchemla F, Popova OM, Agoltsov VA (2017) Analysis of spatial dynamic of epizootic process of bluetongue and its risk factors, Veterinary World, 10(10): 1173-1183.

\begin{abstract}
Aim: The study was undertaken to find out the spatial dynamic occurrence and patterns of the global spread of bluetongue (BT) disease for the period from 1996 to 2016, as well as the assessment of the risk of occurrence and its spread in 2017-2018.

Materials and Methods: Outbreaks (serum samples were collected from clinically healthy as well as suspected animals in infected points) were confirmed and reported officially by veterinary departments which represent different geographical regions in the world to World Organization for Animal Health. These reports explained that ELISA and polymerase chain reaction were used to identify the BT disease, taking in the account number of infected, dead animals, and focus of BT infection in all susceptible animals from 1996 to 2016. Once conventional statistical population was defined (an observational study), we had classified data as well as possible to answer to our aim, using descriptive statistics methods, including the test of the relationship between different epizootiological indicators.
\end{abstract}

Results: The spatial dynamic study of BT's occurrence and its spread in the world over the two past decades was presented by different epizootic indicators. The given analysis includes assessment and measurement of risk factors. It was built too, regression models, and allowed to put different forecasts on the different epizootic indicators in the years 2017-2018 by the extrapolation method. We had also determined that, in 2017, BT continues to spread with the total expectancy of 3.4 focus of infection (number of diseased animals in a single unfavorable point) and mortality of about $26 \%$; these rates tend to decrease in 2018. At abused points by BT, up to $78.4 \%$ of animals are mixed (more than one type) and in $21.6 \%$ - uniform. By this way, the relative risk of the incidence of appearance-abused points in mixed households has 3.64, which might be considered higher for the BT dissemination. Moreover, between the enzootic index and other epizootiological indicators had revealed an inverse correlation, i.e., to an increase in the level of enzootic index among the cattle population would be formed population less sensitive to BT. Cluster analysis was done, which had demonstrated the zoning of risk levels in the world and the occurrence of the disease intensity in the period 1996-2016 years. Then, assess connection degree of the dynamic of BT tension with geographical and socioeconomic conditions background 0.66 and 0.68 , respectively.

Conclusion: It is important to define a variety of BT risk factors and assess their influence on BT occurrence. However, the most important is to define the overlapping coinfluence between them that cause serious losses. To have an out of BT territory needs to make an emphasis of co-influence of risk factors on this zone. Was predicted a continue hits of disease in the next year with weight moderation through one year. Far from statists, to assess the given forecast may have a serious variety, taken in account problems of actual climate change in the world.

Keywords: bluetongue, extrapolation, outbreaks, regression model, risk factors.

\section{Introduction}

Bluetongue (BT) recorded by the World Organization for Animal Health (OIE), included in the list $\mathrm{A}$, which relates to the number of highly dangerous and widespread infectious diseases in the world, has also significant socioeconomic issues in international trade [1-5]. According to the OIE data, BT dispersion is relevant in all continents, particularly,

Copyright: Bouchemla, et al. Open Access. This article is distributed under the terms of the Creative Commons Attribution 4.0 International License (http://creativecommons.org/licenses/ by/4.0/), which permits unrestricted use, distribution, and reproduction in any medium, provided you give appropriate credit to the original author(s) and the source, provide a link to the Creative Commons license, and indicate if changes were made. The Creative Commons Public Domain Dedication waiver (http:// creativecommons.org/publicdomain/zero/1.0/) applies to the data made available in this article, unless otherwise stated. where developed sheep breeding. By the occurrence of BT, in the advantaged areas, morbidity and mortality rates sometimes reach $100 \%$, with the possibility of stationarity of outbreaks [6,7].

A mass BT outbreak annually is estimated in minimum at 3 billion of dollars [8]. In India in 2005 , the disease has covered 280,000 heads of sheep, in Italy (2013) more than 326,000 heads of sheep, with a mortality rate $40 \%$, and in the neighboring country - Greece, in 2014, happened a similar situation [1,7,9-11].

It more than one and half century from scientific acquaintance with the first serotype of bluetongue virus (BTV), and until, this moment has been discovered 27 serotypes [12] and probably the $28^{\text {th }}$ serotype in South Africa recently (personal communication 
with Zientara Stéphan). By the time, BT gets spread in the entire world in a different incidence. In the last BT season had been reported more than 4700 outbreaks in 15 countries in the world (just in Europe 4560 outbreaks in 9 countries). BTV hurts more sheep and goats (in $92.9 \%$ ) than cattle, although more than $64.28 \%$ of susceptible livestock in disadvantages points were cattle. In the past decades, dynamic of occurrence not only BT but also other transmissive diseases has shown an interesting evolution by time and spatial. It is why we focus our epizootical approach to determine BT factor of risk and make a schema to this situation and expected forecasts.

\section{Materials and Methods}

\section{Ethical approval}

Ethical approval was not applicable for this study.

\section{Samples collections}

Outbreaks (serum samples were collected from clinically healthy as well as suspected animals in infected points) were confirmed and reported officially by veterinary departments which supervise conformed geographical regions in each country in the world to OIE. These reports explained that ELISA and polymerase chain reaction were used to identify the BT disease, taking into account number of susceptible, infected, dead animals, and focus of BT infection from 1996 to 2016 [10,13].

\section{Statistical analysis}

The data on the different indicators of BT and their growth dynamic were processed according to the guidelines on conducting epidemiological monitoring of exotic, very dangerous, and unknown diseases, taking into account the OIE Animal Health Code $[14,15]$ with the level of significance set at 5\% to determine differences in test, and they were analyzed with regression using Microsoft Excel 2013. Cluster analysis was built with Excel 2013 too.

\section{Tests}

Once conventional statistical population was defined (an observational study), we had classified data as well as possible to answer to our aim, and it was used.

Coefficient association test to define how connects animals holding manage with BT occurrence. Moreover, by this way, we could know not only the relative risk (RR) of the incidence but also we could have assessment and measurement of risk factors and more commonly used: Linear correlation coefficient: Rang $\mathrm{r}_{\mathrm{s}}$ and Bravais-Pearson $\mathrm{r}$. Used coefficients similarly show the dependence of the BT stationarity on incidence, focus of infection, and lethality as in cattle, as small cattle.

To calculate the connection degree of the dynamic of BT tension with geographical and socioeconomic conditions was used methods of hypothesis testing, criterion $\chi^{2}$, and calculation of the influence force of various systems of factors (entropy of random diversity and total entropy of the complex).

Regression models were used to put different forecasts on the different epizootic indicators in the years $2017-2018$ by the extrapolation method.

The cartographical spatial dynamic study (cluster analysis) was conducted with Microsoft Excel 2013 and QuickMAP program (geoinformation systems).

\section{Results and Discussion}

During the period 1996 - (April) 2016, BT has been registered in 12 countries of the African continent (with 3987 outbreaks), 28 countries of Europe (156993 outbreaks), 9 countries in Asia (5684 outbreaks), and $<0.001 \%$ of the remaining outbreaks spread in the rest of the world. European countries captured up $94 \%$ of all outbreaks, where it had been infected 1.5 million animals with more than $28 \%$ lethality (Table-1).

Using the available data, to study, the spatial dynamic of BT's evolution process was formed a complex of cartograms and diagrams to describe the situation.

Visual analysis of cartograms (Figure-1a) leads to conclude that the highest risk of registered BT is characteristic of the Mediterranean region and South Africa, as well as in Western Europe and the Indian subcontinent, where the registered incidence was higher than the world average (240 outbreaks). In the Middle East, Russia, and South America, the probability of the disease occurrence was less than the average bar in the world. For the Russian Federation, regions with the highest risk of BT are generally situated in the European part, and for Canada, regions closed to the boundary with the United States (we have not had data on the USA).

The highest risk of registering cases of BT (Figure-1b) is typical for the regions of Western Europe, Mediterranean, South Africa, and India, where the probability of above average registration of BT was more than 1783 heads. In America and Australia, the probability of occurrence of the disease had bellowed level face the average in the world.

In Figure-1c, regions with the losses mind are India (more than $20 \%$ of word's loss), the Mediterranean basin, and in recent years, Eastern Europe, where BT encompasses thousands of animals from season to another (average value 731.57 heads), as cattle as small ruminants were seriously infected. In the countries of northern Europe, Russia, and Middle East, losses reduced to 0.5 heads per season.

Visual analysis of clustering with data about wild animals (Figure-1d) leads to the conclusion that the highest risk of BT registered among wild animals typical for Europe and South Africa in the first time, with a high risk of virus circulation among native wild populations, and in a less degree in India and Palestine, where the probability of virus isolation did not reach the world average value. In the central regions of America, Australia, and Africa, the risk of occurrences disease exists $[1,4,10,16-19]$. 
Table-1: The global spread of bluetongue in the world from 1996 to 2016.

\begin{tabular}{lcccc}
\hline Continent & $\begin{array}{c}\text { Number of disadvantaged } \\
\text { countries (\%) }\end{array}$ & $\begin{array}{c}\text { Number of } \\
\text { outbreaks (\%) }\end{array}$ & $\begin{array}{c}\text { Number of diseased } \\
\text { animals (\%) }\end{array}$ & $\begin{array}{c}\text { Number of dead } \\
\text { animals (\%) }\end{array}$ \\
\hline Australia & $1(2)$ & $4(0.002)$ & $10(0.001)$ & $3(0.001)$ \\
America & $5(9)$ & $9(0.005)$ & $108(0.005)$ & $39(0.008)$ \\
Asia & $9(16)$ & $5684(3.410)$ & $547997(27.568)$ & $114918(22.183)$ \\
Africa & $12(22)$ & $3987(2.392)$ & $37120(1.867)$ & $9781(1.888)$ \\
Europe & $28(51)$ & $156993(94)$ & $1402575(71)$ & $393302(75.921)$ \\
All the world & $55(100)$ & $166677(100)$ & $1987800(100)$ & $518043(100)$ \\
\hline
\end{tabular}

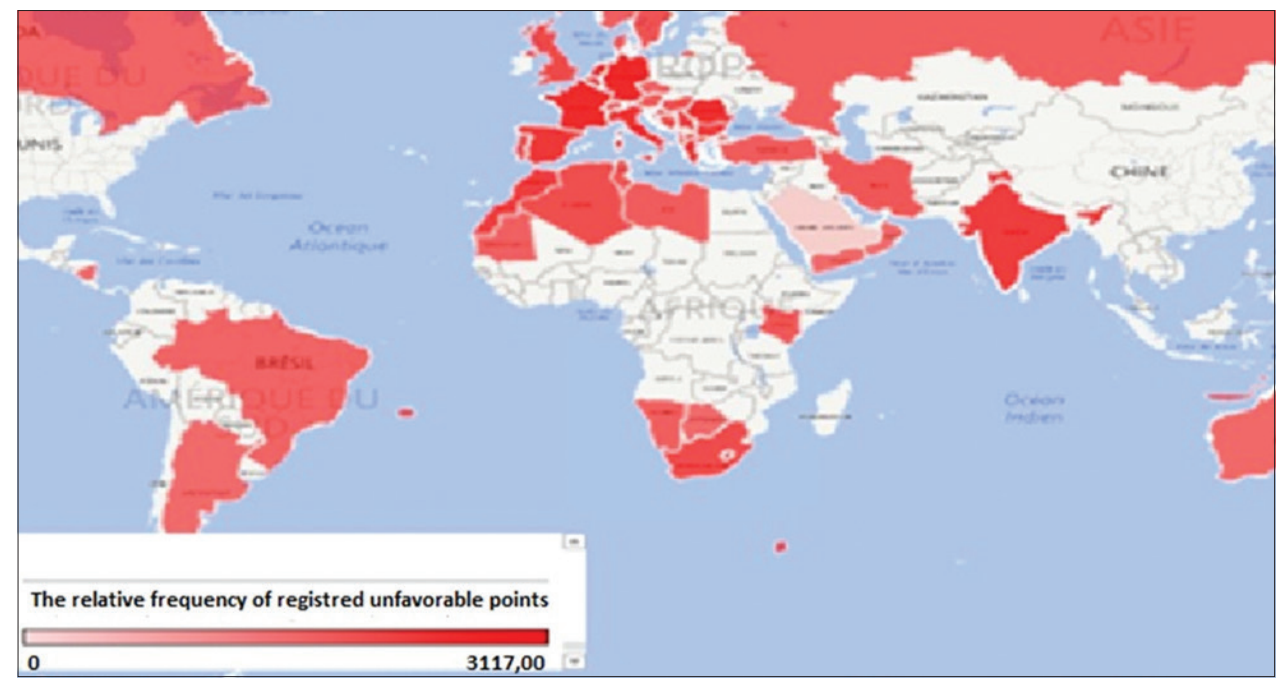

Figure-1a: Clustering BT-risk areas in the world in the period from 1996 to 2016 years.

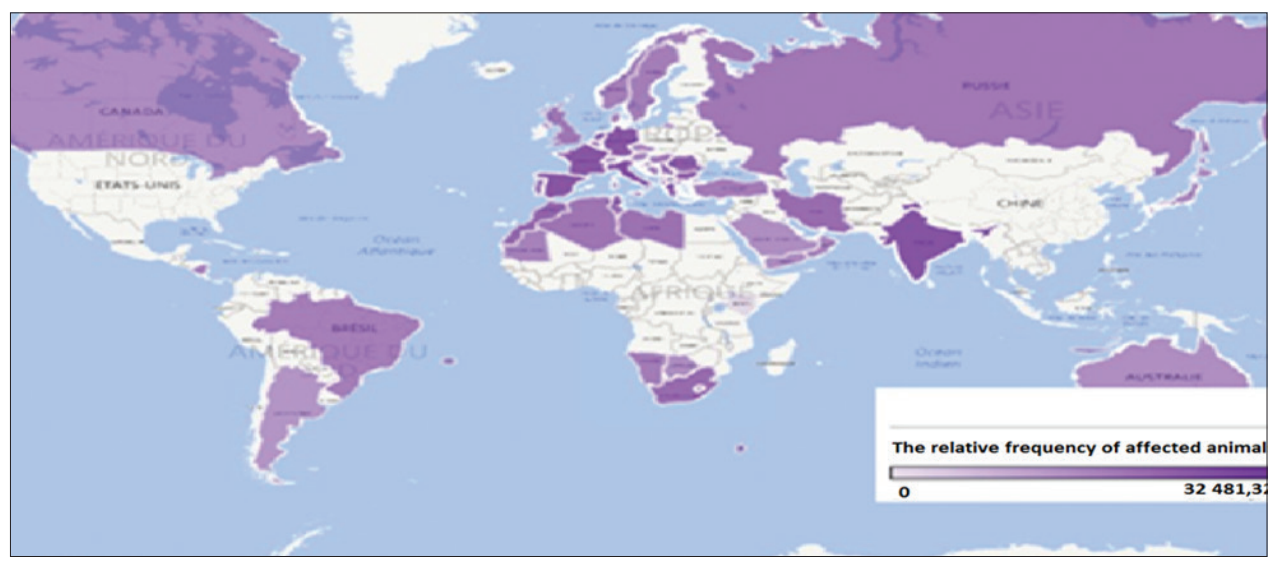

Figure-1b: Cartogram BT cases in the world in the period from 1996 to 2016 years.

The tension of the epizootic situation was identified too, by indicators of the incidence of cases and outbreaks in disadvantaged countries.

Any variation of this distribution (Figure-2) is so important characteristics of the epizootic state of population. These variations can be a form of "dome" and "tails" (shallow and steep), uni- or polymodal (one or more packs), and asymmetry, i.e., the displacement of values on the chart in the increasing or decreasing direction expressing studied trait, limits, or volume of distribution, i.e., the range between the extreme values (as wider distribution as makes the more stable character).

From Figure-2, rather noticeably polymodal of the curve as wives, explaining the way to the emergence of the episodic BT process. It is also observed that the size of these waves has not a constant option (asymmetry), and their base closely varies in short intervals of 2-3 years. The nature assortment of the virus complicates, eradicates it, and gives another possibility of all sorts, including those in the new territories may explain this. In the same way, we cannot exclude the latent introduction.

The coincidence of the periods of decline and rise between defeat (infected heads) and lethality indicates a certain relation between themselves. It was confirmed with correlation coefficient (equal 0.94) - direct and strong link.

Periods of remission accompanied with a closed widespread; in 1997, BT was present only in 


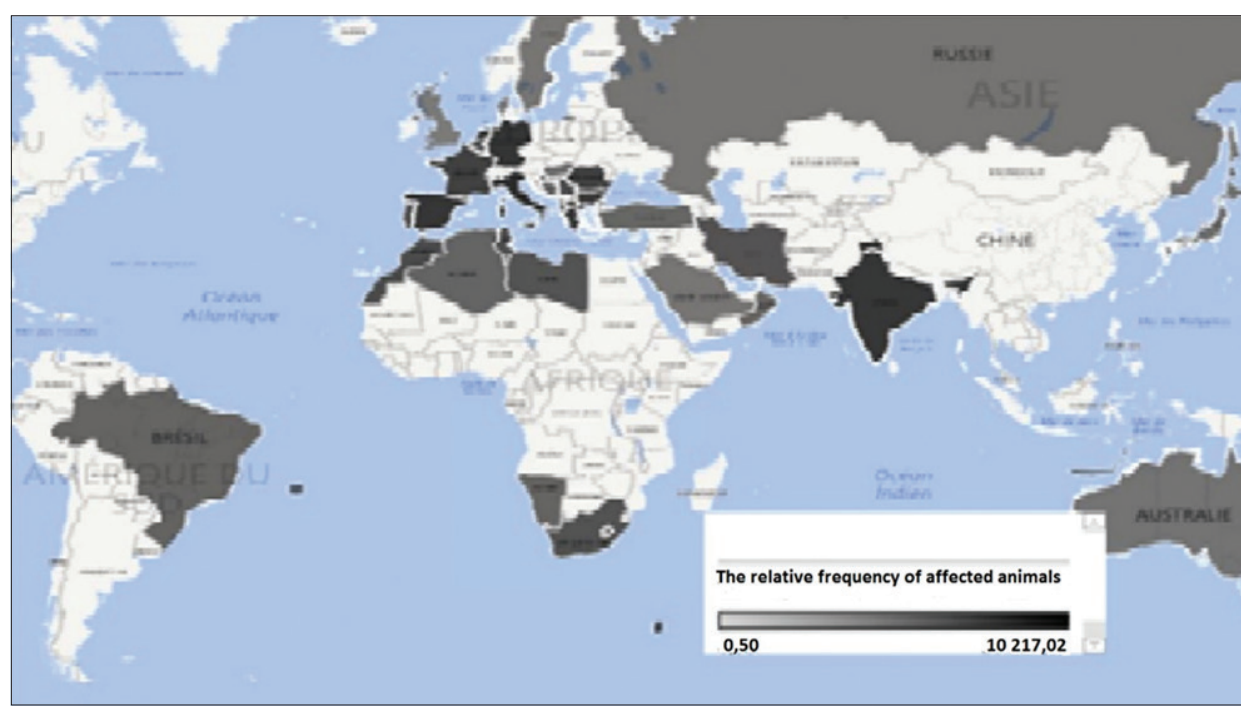

Figure-1c: Clustering losses related to BT in the world in the period from 1996 to 2016 years.

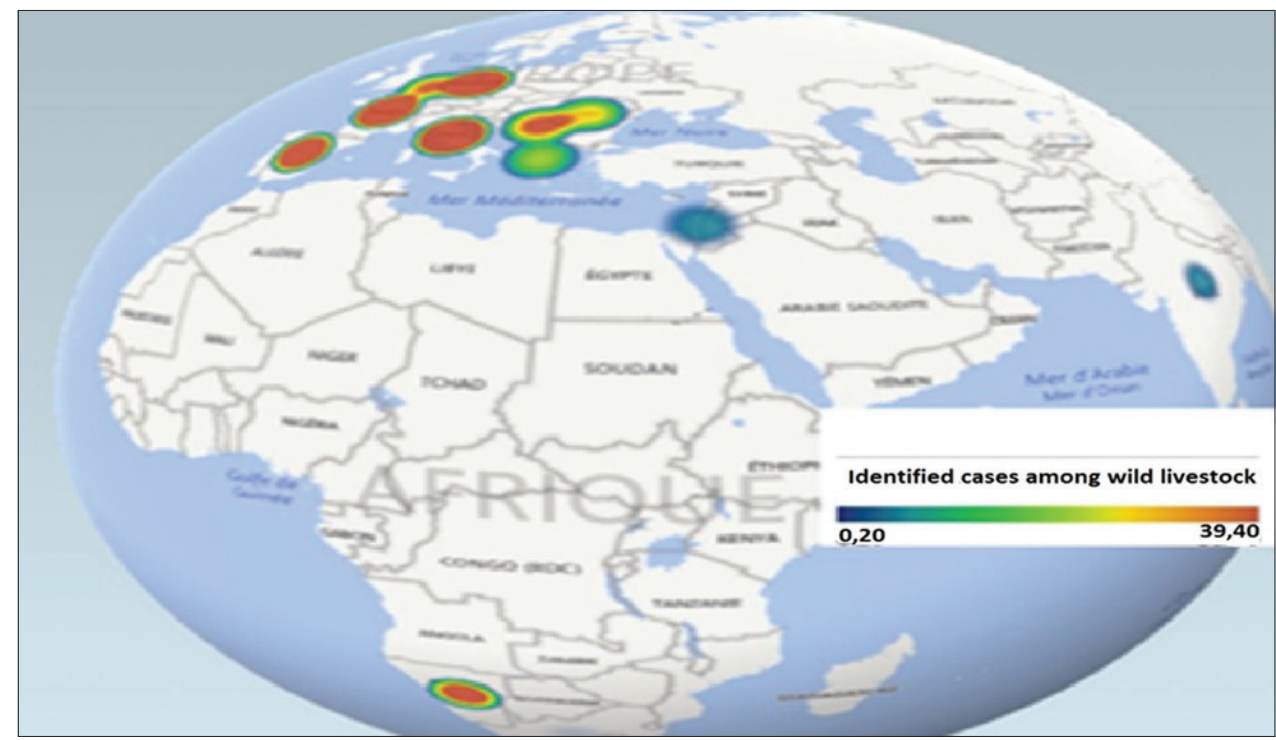

Figure-1d: BT's prevalence of the wild population in the period from 1996 to 2016 years.

6 countries around the world, and in 2004-2005, in 8 countries, and vice versa, but conversely, in 20092011 , more than 20 countries announced his disadvantaged by BT, and 15 countries in 2016 .

Knowing the features of any disease is the key to its eradication and besides, if it is expected. Therefore, we tried to build regression models of different indicators to predict the expected future situation on 2017-2018 years.

Construction of curves for different indicators shows large variations that complicated our task in their approximation (for trend line) and may not allow for reliable forecasts.

One-off the test function is selected; the next step would be choosing the function parameters giving as possible a good approximation to the experimental points (approximation ratio $\mathrm{R}^{2}$ ). In the order to obtain, a high $\mathrm{R}^{2}$ value was counted up more moderate functions (smoothing averages over three consecutive points [or smooth down 5 if necessary]), which more appropriate in such case, to give a more moderate form of regression models that improve the value of $\mathrm{R}^{2}$.

Regardless of the $\mathrm{R}^{2}$ value, the use of the obtaining models was as an extrapolation to predict the expected situation. The results are shown in Tables-2 and 3 and Figures-3-5.

All charts of the $3^{\text {rd }}$ figure demonstrate 4 large episodic: In 2000, 2005, 2007, and 2014, in which economic losses were very noticeable. Although chart's progress varied with a less asymmetric multimodal that complicates build a regression model. Access to the average grading rules (smoothing) had helped building different models, whose extrapolation for 2017 posted in Table-2.

Seeing our previous analytics of the dynamics of BT prevalence and losses from until 2016, expected wave should be regenerate, and the results of this table have just been suit this dynamic. They can be compared with the packs of other waves. Hence, at the table, we may predict what will be expected from BT 
focus of infection with 3.37 and lethality rate around $25 \%$ in 2017 . Moreover, all these indicators tend to decrease (not sharp) in 2018 globally.

Since BT affects small cattle, as well as cattle, and other species of wild population [4,5,10,13,14,19-28], we had tried to study separately the different expected epizootic parameters in small cattle (and cattle) in the following 2 years, to lodge with finest possible forecasts. The obtained results are shown in Table- 3 and Figures-4 and 5.

From Figure 4a, may be concluded that the incidence index in small cattle was expressing freestyle different sizes (83-19), and with the base almost homogeneous (2-3 years). To avoid large variation of size was necessary building a medium-sized smoothing of 5 followed points (values):

Obtained model: $Y_{t}=0.0116 x^{3}-69.688 x^{2}+13961$ $8 \mathrm{x}-9 \mathrm{E}+07$

Where $Y_{t}$ - Value of models of the dynamics epizootic situation,

Table-2: Extrapolating results of epizootic outbreaks, infected animals in and death on 2017.

\begin{tabular}{lc}
\hline Prevalence & ++ \\
\hline Outbreaks (points) & 112747.69 \\
Infected animals (heads) & 379571.32 \\
Dead animals (heads) & 97597.51 \\
\hline
\end{tabular}

Table-3: Predict of results by extrapolation models of morbidity, lethality, and focus of infection on 2017-2018 years.

\begin{tabular}{llcc}
\hline Indicators & Animal species & $\mathbf{2 0 1 7}$ & $\mathbf{2 0 1 8}$ \\
\hline Morbidity (\%) & Small cattle & 19.49 & 14.52 \\
& Cattle & 88.99 & - \\
Lethality (\%) & Small cattle & 1.014 & 15.59 \\
\multirow{3}{*}{ Focus of infection } & Cattle & 11.45 & 38.1 \\
& Small cattle & - & - \\
& Cattle & 148.2 & - \\
\hline
\end{tabular}

-=Negative value $\mathrm{x}$ - The serial number of the year.

$\mathrm{R}^{2}=0.7$ demonstrates a great approximation.

Model of theoretic values had comforted to 2014, where the value also increasing a bit and become $19.5 \%$ in 2016, and then, will reduce to $14.52 \%$ in 2018 (Table-3).

Interpretation of the curves of Figure-5a shows that curve asymmetric and not so polymodal. However, interested outbreaks can be registered forward. The cycle of corresponding model has varied from 12 to 15 years. It should be noted that this model has to rise in the near future.

In our case, it had seen that lethality had strong connection with mortality (correlation coefficient $r=0.94)$, therefore, every change of one index, other index will automatically change. Especially, can see this link at comparison of these indices (for example, in the small cattle, Figure-4a and $4 b$ ). Furthermore, the same conclusions can be said about dynamics of conformed models, in 2017, expected "morbidity - lethality" in small cattle 19.5-1.49\%, and in 2018, both reduced at $14.52 \%$ and $15.6 \%$ (Table-3).

The criterion of the focus of infection shows the intensity of infection in any disadvantaged point. Moreover, in this situation, these curves of both types of animals are different, which suggest that the emergence of BT process includes many factors, some of these have a strong influence (Table-4) and other - weight influence. Only, their interaction together can determine the type, the occurrence of episodic and even geographical distribution.

In addition, there is an internal interaction - between epizootic indices among themselves, with their reference to the weight influence factors (Table-5). They cannot generally specify the episodic cases about whose we discussed.

According to Table-3, it is well shown that the expected incidence of morbidity and focus of infection in both species in 2017-2018 will reduce but mortality rate, especially in small cattle, will be rising.

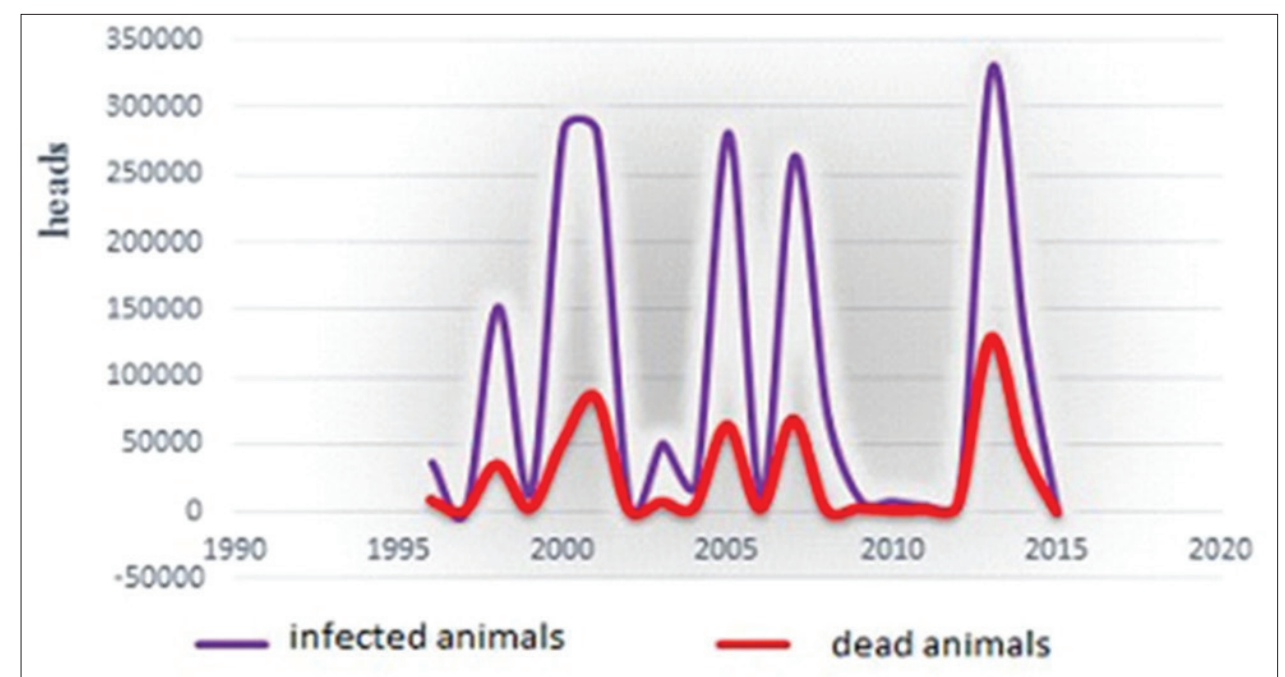

Figure-2: BT's prevalence of the wild population in the period from 1996 to 2016 years. 


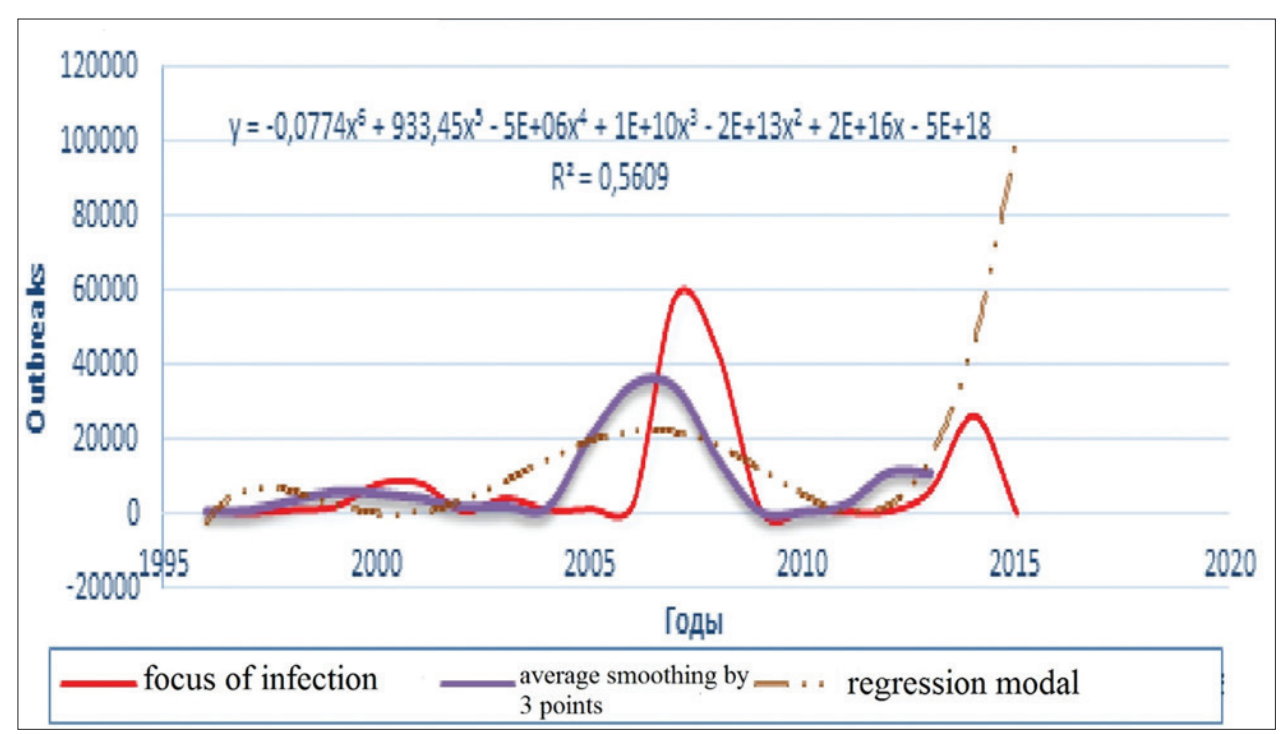

Figure-3a: Dynamics of BT outbreaks in the period 1996-2016, average smoothing and its regression model.

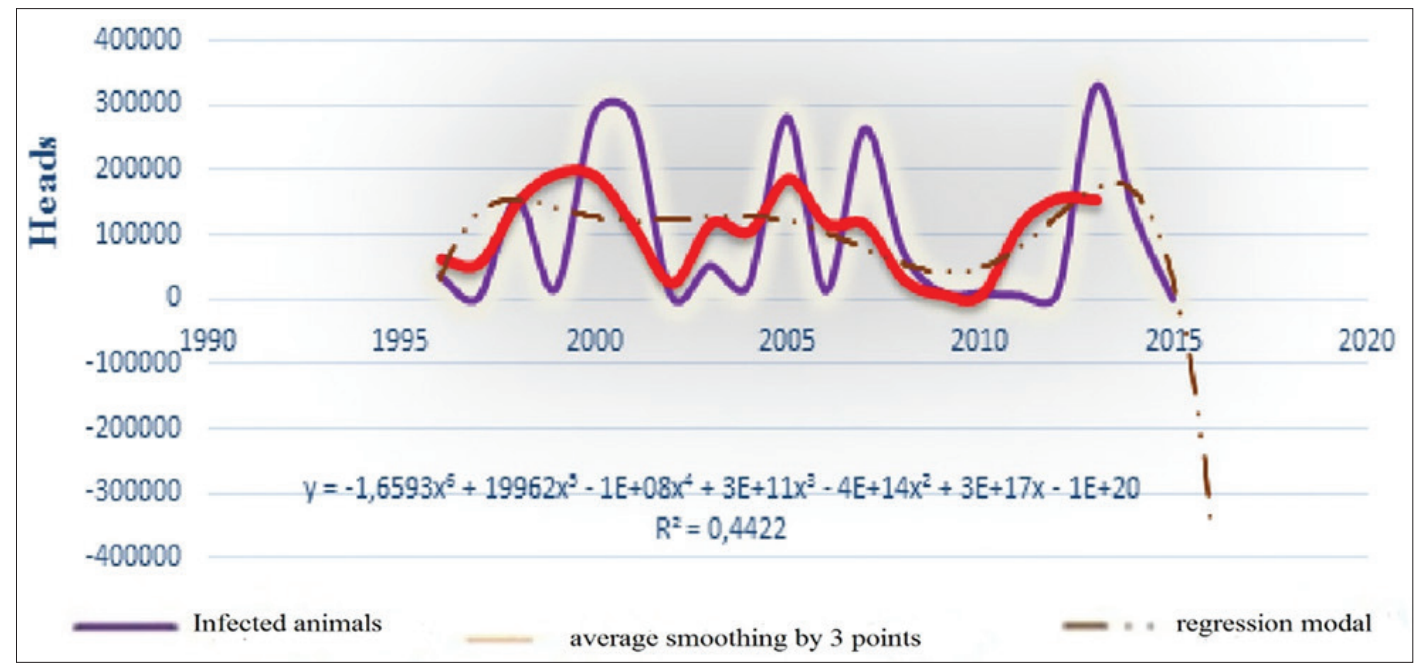

Figure-3b: Evolutionary prevalence of BT, average smoothing and its regression model from 1996 to 2016 in the world.

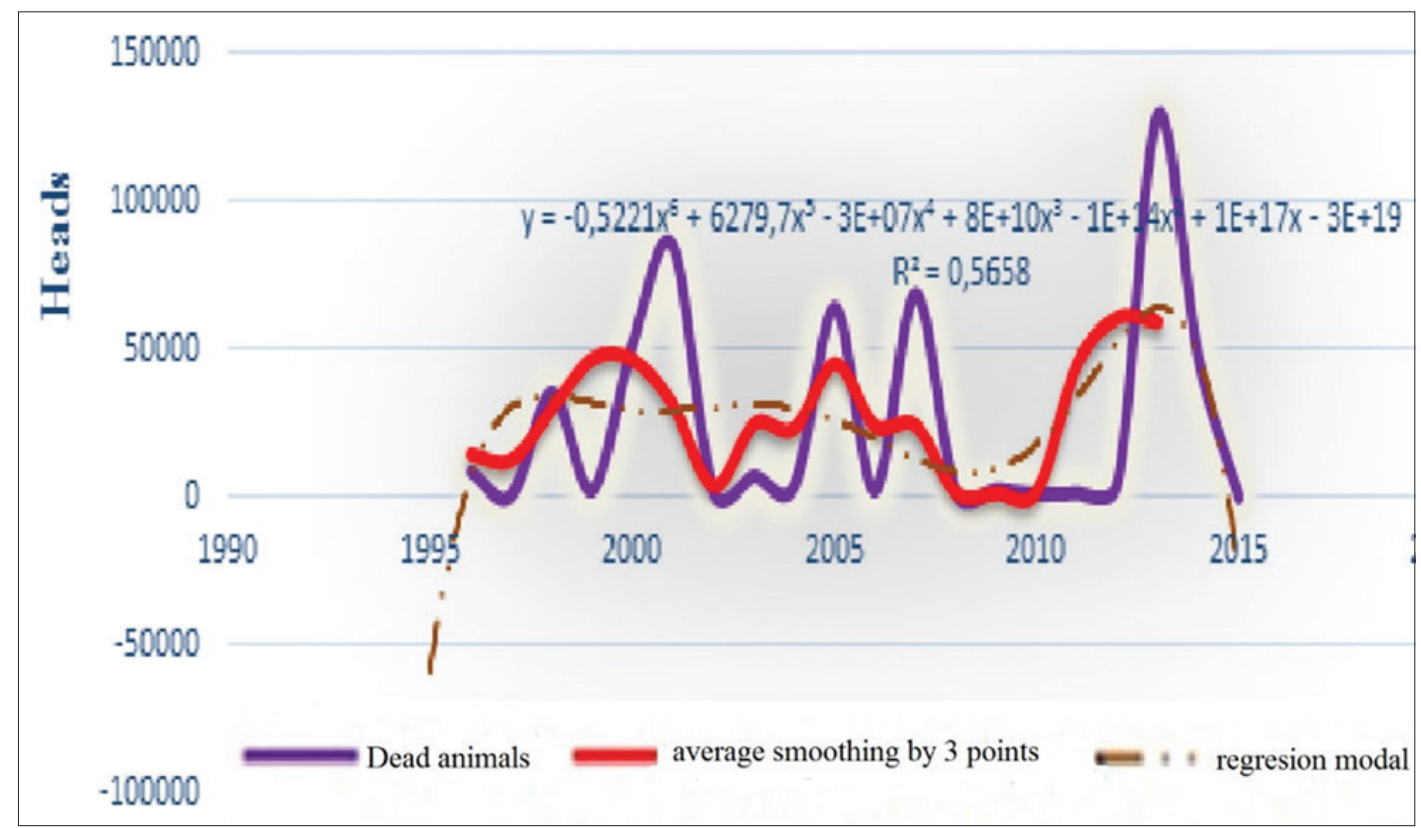

Figure-3c: Dynamic of BT lethatity, average smoothing and its regression model from 1996 to 2016 in the world. 


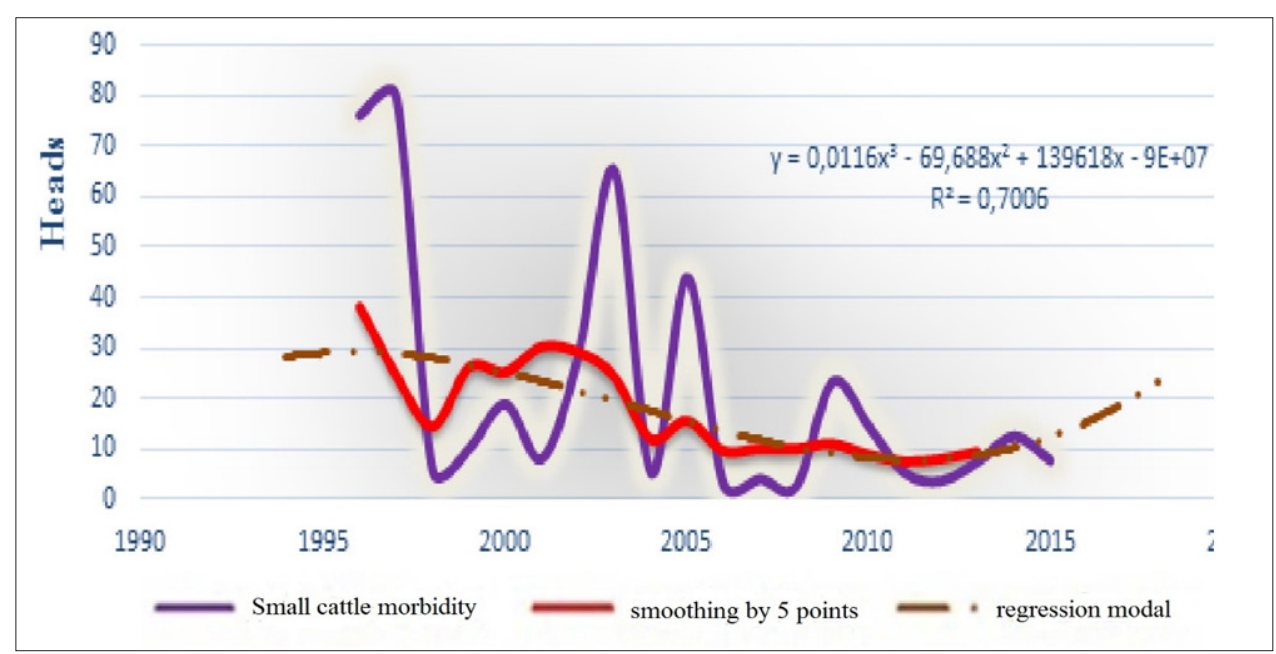

Figure-4a: Dynamic, average smoothing and its regression model of the BT episodic morbidity in small cattle for the period 1996-2016 in the world.

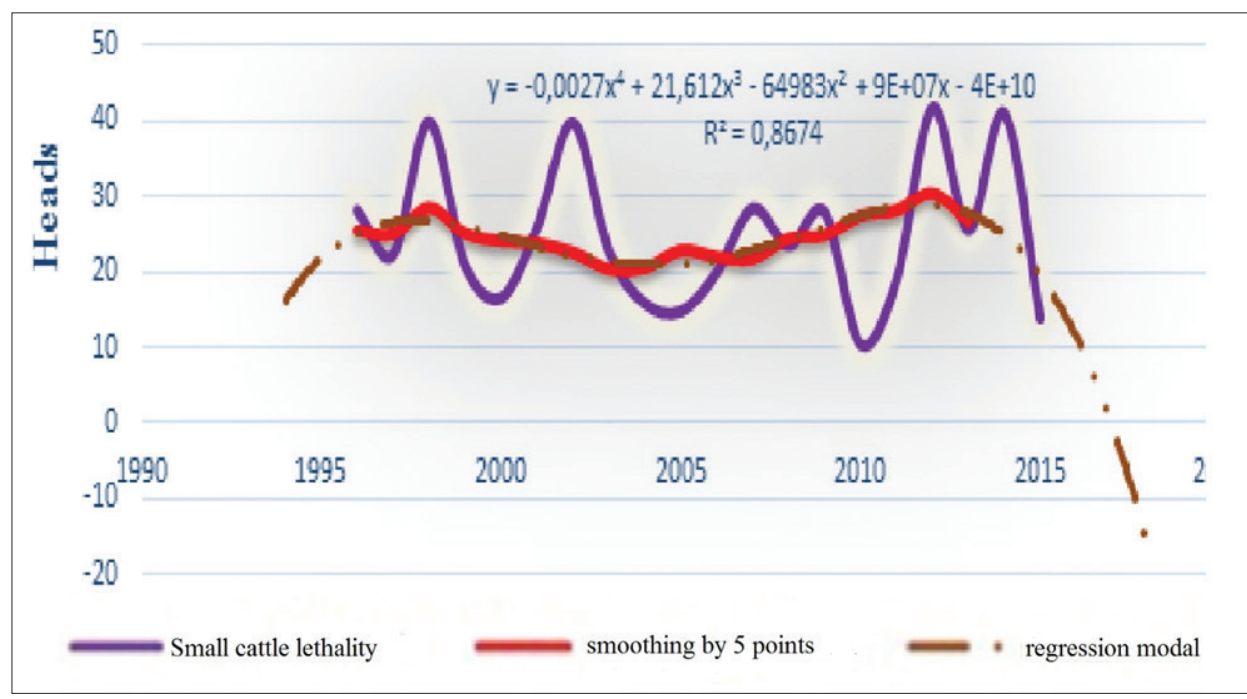

Figure-4b: Chronology of dynamics, average smoothing and its regression model of the BT lethality in small cattle for the period 1996-2016 in the world.

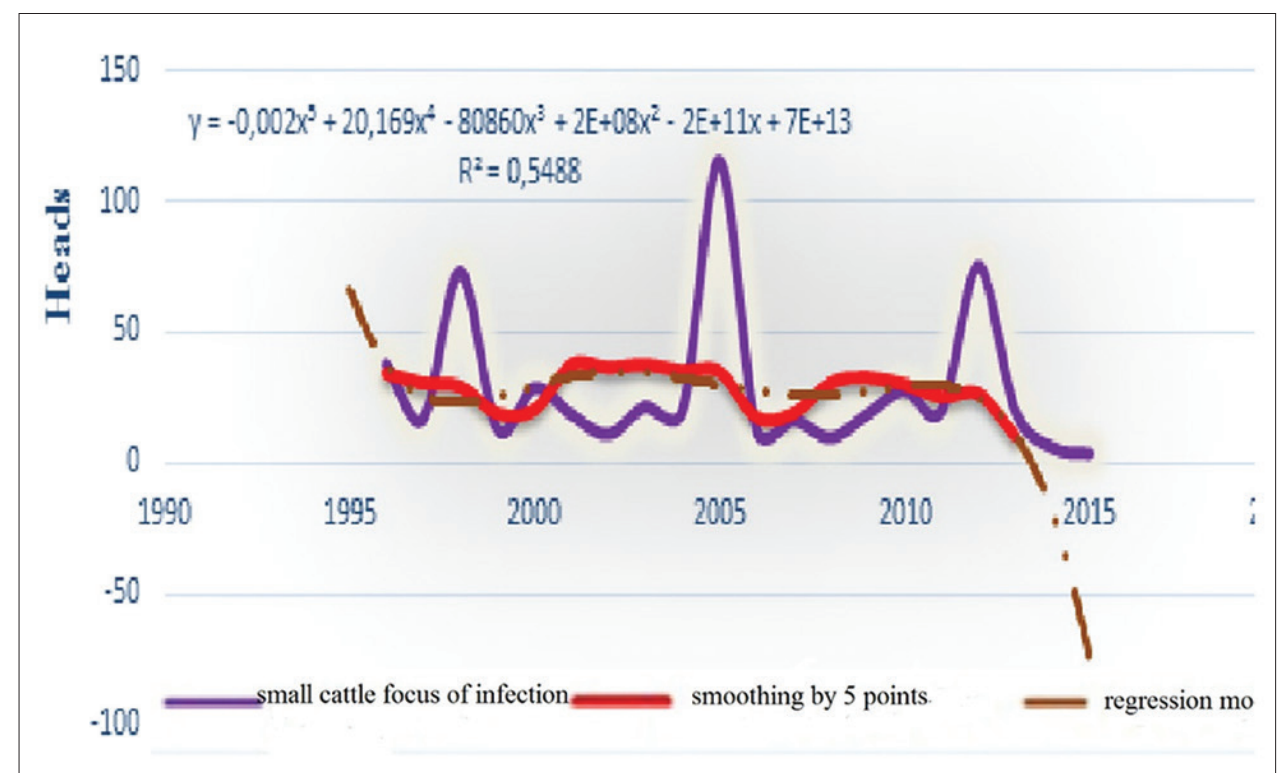

Figure-4c: Dynamics of BT focus of infection, average smoothing and its regression model of the in small cattle for the period 1996-2016 in the world. 


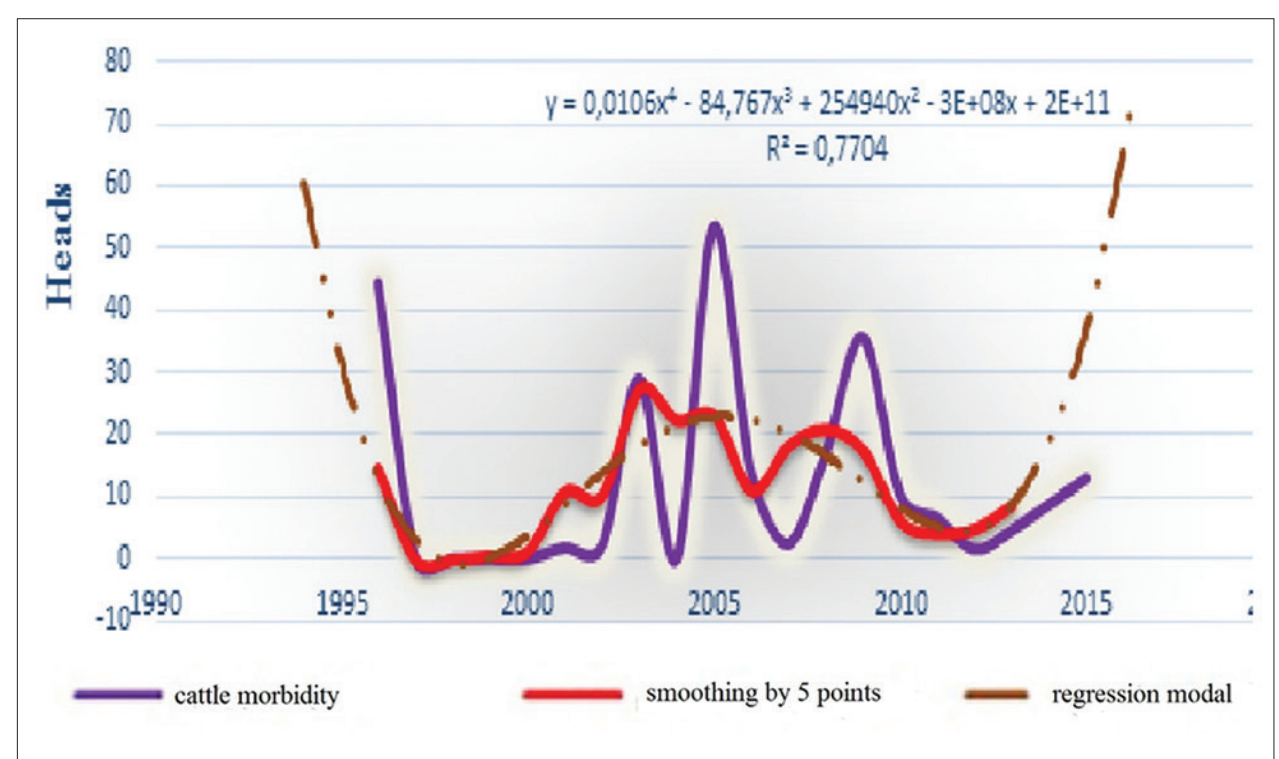

Figure-5a: Dynamic, average smoothing and its regression model of the BT epizootic morbidity in cattle for the period 1996-2016 in the world.

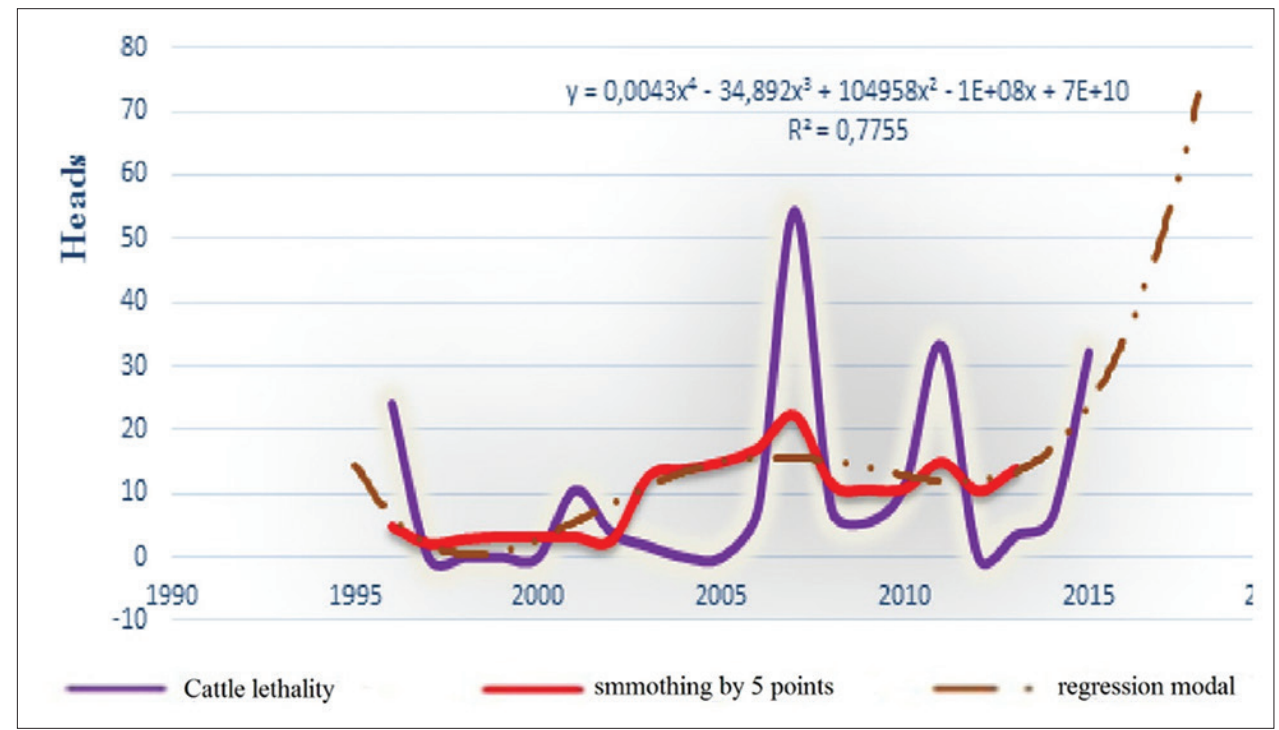

Figure-5b: Chronology of dynamics, average smoothing and its regression model of the BT lethality in cattle for the period 1996-2016 in the world.

The main complexity of the BT epizootic resides in the length of the virus circulating in the reservoir of infection and the manifestation of the disease in all (epizootic, enzootic, and sporadic) forms, and their transitions one form to another.

Although BT sources and transmission paths are well known, in some cases, they could be so diverse, depending on the purpose and intensity of cultivation of animals, their description is only relevant to a concrete case (outbreak). Table-4 was created to determinate the participation share of BT factors in transmission.

Using available data from epizootic outbreak, investigations in different farms made an attempt to quantify the skidding BT ways. Information was gathered on the main routes of transmission of BTV, established at the epizootic outbreaks between 1996 and 2016 years (Table-4).
From Table-4, it is obvious that the degree of influence of various factors on the way of the distribution of BT in time is different seen that wintering is an important (48.1\%) factor may qualify as an autosaved virus in cold periods. In our study, the majority of these outbreaks were registered in limited regions and time (2006-2008 years in the Europe), where the main pathogen (serotype 8) appeared with a new virulent approach (hit small ruminant, as well as cattle including wild animals).

Another important factor is considered too important in our opinion; this is the juxtaposition of BT infected points, which causes an increase in biological speed of transmission by vectors. It is the most speared factor in different countries in the world.

The role of trade and wildlife in epizootiology of BT is not significant $(0.09 \%$ and $1.13 \%$, respectively), for the first one due to the strict international 


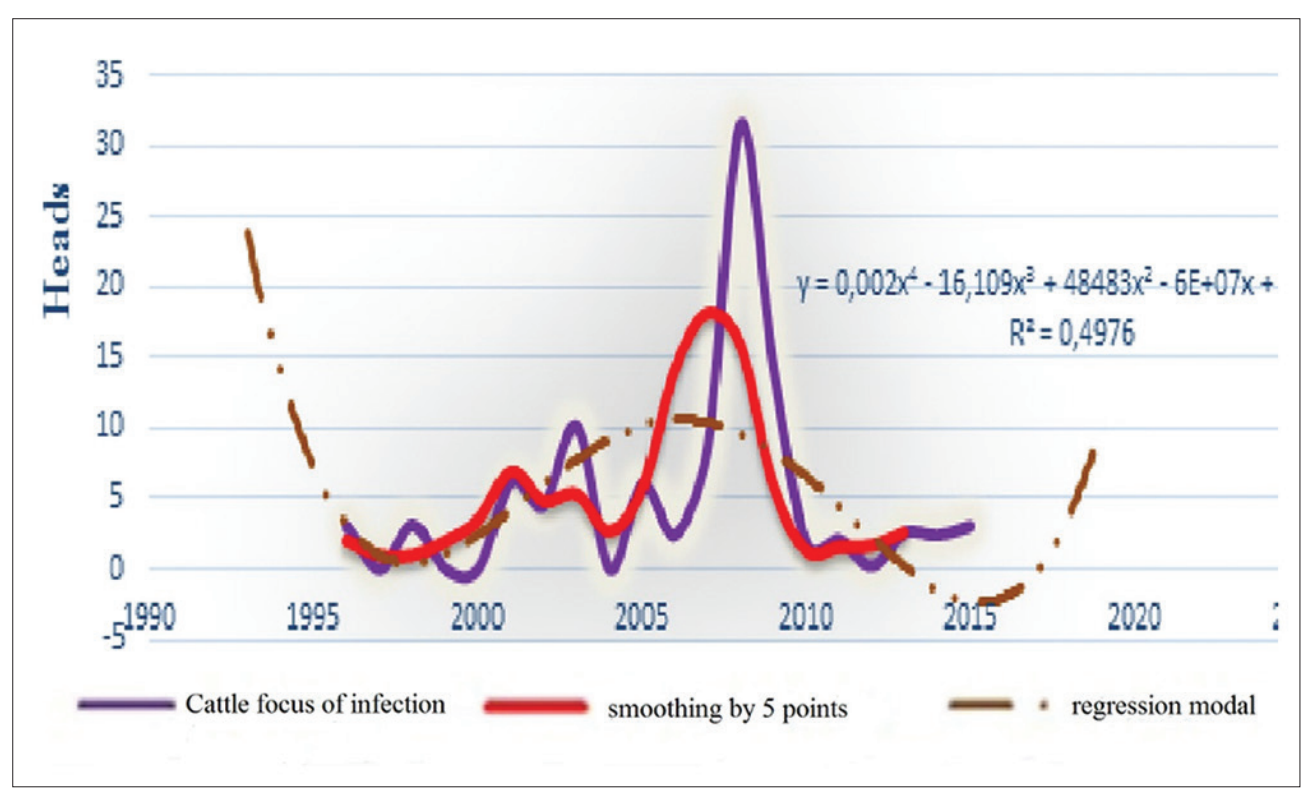

Figure-5c: Dynamics of BT focus of infection, average smoothing and its regression model of the in cattle for the period $1996-2016$ in the world.

Table-4: The main suspects BT transmission established ways during the episodic outbreaks from 1996 to 2016 in the world.

\begin{tabular}{lcc}
\hline \multirow{2}{*}{ Transmission way } & \multicolumn{2}{c}{ Value } \\
\cline { 2 - 3 } & Absolute & $\%$ \\
\hline Geographical proximity & 46325 & 27.9 \\
Trading of infected animals & 147 & 0.09 \\
BT infected wild animals & 1879 & 1.13 \\
Wintering (overwintering) & 79869 & 48.1 \\
Not installed (unknown) & 38457 & 22.77 \\
$\varepsilon$ & 166677 & 100 \\
\hline
\end{tabular}

$\mathrm{BT}=$ Bluetongue

Table-5: The correlation coefficient $(r)$ of epizootic indices interaction between themselves.

\begin{tabular}{lc}
\hline The ratio of the correlation index & $\mathbf{r}$ \\
\hline Morbidity (small cattle) - Lethality (small cattle) & -0.060 \\
Morbidity (cattle) - Lethality (cattle) & 0.015 \\
Morbidity (small cattle) - Focus of & 0.146 \\
infection (small cattle) & \\
Morbidity (cattle) - Focus of infection (cattle) & 0.328 \\
Lethality (small cattle) - Focus of & 0.103 \\
infection (small cattle) & \\
Lethality (cattle) - Focus of infection (cattle) & 0.0787 \\
Morbidity small cattle - Cattle & 0.508 \\
Lethality small cattle - Cattle & -0.117 \\
Focus of infection small cattle - Cattle & -0.141 \\
\hline
\end{tabular}

legislative movement of live animals and their products, and for the second due to a two-fold reason: The difficulty of controlling and identifying incidents among them and their distribution.

It remains to be noted that $22.77 \%$ of cases had unknown cause for us, we had explained this by the no established (studied) factors of BT episodic process during the analyzed period (1996-2016 years). This fact indicates less level of system control in disadvantaged regions. Mainly, this is due to depopulation (active or passive), including wild animals, procurement and systems of rearing animals, especially in private farms (traditional).

Another factor, we tried to know how stationarity effect on BT tension (seeing enzootical factor - repeatability of BT occurrence (number of years) in a particular area to the total observation period). Table-6 presented the results of calculating the degree of stationarity influence on the tense epizootic situation.

The closeness of statistical relations may be determined by various factors (Fisher, Pearson, coefficient association, etc.), and more commonly used: Linear correlation coefficient: Rang $r_{\mathrm{s}}$ and Bravais-Pearson (r). Used coefficients similarly show the dependence of the BT stationarity on the studied indices.

The most significant direct correlation was found between the occurrence of the focus of infection among small cattle and the stationarity index rose $r_{s}=0.91$; it is a very strong and direct connection. This dependence is due to the direct influence of enzootic factor on the occurrence of the focus of infection in small cattle and vice versa, reducing the recurrence of $\mathrm{BT}$ in the local population contributes to the reduction of livestock small cattle with a complex epizootic situation.

An average degree of dependence $\left(\mathrm{r}_{\mathrm{s}}=-0.6\right)$ takes place between the emergence of focus among the cattle and the stationarity index, i.e. to an increase in the level of the stationarity index among cattle formed population less susceptible to the disease (it serves as a vaccine).

A strong degree of indirect rang correlation $r_{s}=-0.7$ (considered strong) was noted between mortality among cattle (small cattle too) and the stationarity index, which is due to the natural immunization of diseased animals during BT epizootic outbreaks was found too, a considerable correlation between the morbidity of cattle and stationarity $\mathrm{r}=-0.66$. 
Table-6: Correlation of stationarity effect - as a specific index of the incidence of cases and outbreaks of BT in cattle and small cattle in the world (1996-2016, statistical significance level $a=0.05)$.

\begin{tabular}{|c|c|c|c|c|c|c|}
\hline \multicolumn{7}{|l|}{ Indicators } \\
\hline \multirow[t]{2}{*}{ Stationarity } & \multicolumn{2}{|c|}{ Morbidity } & \multicolumn{2}{|c|}{ Lethality } & \multicolumn{2}{|c|}{ Focus of infection } \\
\hline & Small cattle & Cattle & Small cattle & Cattle & Small cattle & Cattle \\
\hline$[0-0.2]$ & 7.61 & 17.92 & 33.26 & 19.62 & 9.25 & 5.01 \\
\hline$[0.2-0.4]$ & 11.45 & 3.25 & 29.71 & 12.09 & 19.55 & 6.87 \\
\hline$[0.4-0.6]$ & 9.83 & 12.91 & 36.23 & 3.11 & 13.19 & 174.66 \\
\hline$[0.6-0.8]$ & 14.31 & 4.37 & 29.37 & 0.12 & 35.81 & 4.7 \\
\hline$[0.8-1]$ & 7.66 & 3.51 & 22.02 & 6.96 & 48.44 & 4.25 \\
\hline The rang coefficient $r_{s}$ & 0.3 & -0.4 & -0.7 & -0.7 & 0.9 & -0.6 \\
\hline Correlation coefficient $r$ & 0.17 & -0.66 & -0.68 & -0.76 & 0.91 & -0.01 \\
\hline
\end{tabular}

BT=Bluetongue

It was revealed a weak positive correlation between the degree $(r=0.3)$ of the dynamic of morbidity among small cattle and stationarity, due to the emergence of different serotypes of BTV. Although there is less cross-immune protection, apparently, it seems that there is an influence of other factors, no studied here.

Thus, it could be concluded that the stationarity index carries somewhere, character of natural vaccination, but with more severe losses.

\section{Effect of animal homogeneity breeding on the struc- ture and the risk of $B T$}

$\mathrm{H}_{0}$ null hypothesis testing procedure had been verified for data: (Chi-square test) $\chi_{\text {obs }}^{2}=54.83$ and $\chi_{\text {crit }}^{2}=3.84 . \chi_{\text {obs }}^{2}$ value is falling into the critical region: $\chi^{2}>\chi_{\text {crit }}^{2}$, so the $\mathrm{H}_{0}$ hypothesis is rejected with an error probability of $\alpha 5 \%$, and thus, both indicators are considered dependent. Mathematical calculations have confirmed that the connection to the BT susceptibility of small cattle is strong and direct (association rate $=0.72$ ).

Table-7 presented an analysis of the BT risk distribution of infected points by homogeneous breeding livestock (one or more kind of animals in holding) for the period from 1996 to 2016. In real terms, immediate risk (attributive or extensive) is the difference between the absolute indicators (morbidity) of control and experimental groups, and the RR - their ratio. It was found that the RR of BT in a small cattle equal 20.76 (immediate risk=11 and at odds $=12.75$ ).

RRs frequency of BT infected points in the same period under the influence of factors - type of breeding (mixed or no) were greater than one and grew up to 3.64, which can be considered a high level of danger for spreading $B T$, with an excess risk $\left(\mathrm{R}_{1}-\right.$ $\mathrm{R}_{0}=0.56$ ) during the breeding of each species of animals separately.

\section{Analysis of the impact of socioeconomic and geo-} graphic conditions on the BT's intensity

In carrying out, epidemiological analysis took into account a range of indicators of socioeconomic factors that reflect the level of socioeconomic development of regions [23].

The results of the analysis of the BT structural area derived from an assessment of the impact of
Table-7: Analysis of the distribution of risks for BT infected points by homogeneous breeding livestock for the period 1996-2016.

\begin{tabular}{lccl}
\hline $\begin{array}{l}\text { Type of } \\
\text { breeding }\end{array}$ & \multicolumn{2}{c}{ Outbreaks } & Risk \\
\cline { 2 - 3 } & + & Total & \\
\hline Mixed & 130236 & 166034 & $\mathrm{R}_{1}=130236 / 166034=0.78$ \\
Homogeneous & 35798 & 166034 & $\mathrm{R}_{0}=35798 / 166034=0.22$ \\
\hline BT $=$ Bluetongue & &
\end{tabular}

BT=Bluetongue

Table-8: Impact of socioeconomic and natural conditions on the intensity of the BT epizootical situation (by the level of stationarity).

\begin{tabular}{lc}
\hline Factors & The power of influence \\
\hline socioeconomic conditions & 0.66 \\
Geographic-natural conditions & 0.68 \\
\hline
\end{tabular}

BT=Bluetongue

geographical and socioeconomic factors background on the epizootic situation are given in Table-8.

Thus, it was established a statistically significant effect of these parameters on the stationarity index as direct and strong bond, suggesting conditionality. This dependence increases sharply with their synergy. According to the distribution of statistical calculations was found that the BT tensest situation has developed in the Mediterranean region.

\section{Conclusion}

In the BT dynamics of small cattle, symmetry and polymodality are observed at all indexes, which indicate the homogeneity of the epizootic process, and conversely, in the case of cattle, there is an obvious heterogeneity. Participation of wintering phenomena with $48 \%$ in the BT occurrence does not make him the most important factor of risk, but the geographical proximity of infected holding may get it because of wintering which is limited in time and space.

According to the forecast, expected more and more of focus of infection with global moderate mortality up to $25 \%$ (nearly 97600 heads) in 2017 years, and these values tend to decrease (not sharp) in 2018 years. The marked correlation between all risk factors and its coinfluence defines degree in the really expected situation. The occurrence of BT disease on 
new territory may generate as new factors as a new serotype.

It should be emphasized here that such investigation study has to be checked in each geographical region to define local risk factors. Moreover, special attention should be taken to avoid or minimize vector spread reported by geographical proximity above as a main risk factor.

\section{Author's Contributions}

VAA and OMP designed the work. FB conducted the research work. Data analysis and manuscript were written by FB and OMP under the guidance of VAA. All authors read and approved the final manuscript.

\section{Acknowledgments}

The authors are very much thankful to colleagues from mathematic department for providing all necessary helps for conducting this research work. All authors supported this study because it is a personal approach and a part of first author's PhD thesis.

\section{Competing Interests} interests.

The authors declare that they have no competing

\section{References}

1. Bouchemla, F. (2016) Features of the epizootic process of bluetongue in various geographical areas. Author's abstract of can. Dis. Vet. Sci. Kazan., 190: 5-12.

2. Guichard, S., Guis, H., Tran, A., Garros, C., Balenghien, T. and Darren, J. (2014), Worldwide niche and future potential distribution of Culicoides imicola, a major vector of bluetongue and African horse sickness viruses. PLoS One, 9: e112491.

3. Kononov, A.V., Sprygin, A.V., Fiodorova, O.A., Babin, Y.Y., Elatkin, N.P., Mathieu, B. and England, M.E. (2014) Culicoides bitings midges (Diptera: Ceretopogonidae) in various climatic zones in Russia and adjacent lands. J. Vector Ecol., 39: 306-315.

4. Mahmoud, M.A. and Khafagi, M.H. (2014) Seroprevalence of bluetongue in sheep and goats in Egypt. Vet. World, 7(4): 205-208.

5. Pany, S.S., Biswas, S.K., Chand, K., Mohanty, N.N., Sarangi, L.N., Mondal, B. and Panda, H.K. (2016) Antigenic evidence of bluetongue virus from small ruminant population of two different geographical regions of Odisha, India. Vet. World, 9(3): 304-307.

6. Bouchemla, F. and Agoltsov, V.A. (2015) Retrospective analysis and assessment of the bluetongue epizootic situation. Naytch. Jizn., 1: 139-142.

7. Bouchemla, F. and Agoltsov, V.A. (2014) Analysis of the epizootic situation bluetongue in the Mediterranean countries. Ucheniye Zap. KGAVM, 219: 62-69.

8. Tabachnick, W.J. (1996) The genetics of Culicoides variipennis and the epidemiology of bluetongue disease in North America. Annu. Rev. Entomol., 45: 20-40.

9. Chand, K., Biswas, S.K., Pandey, A.B., Muthuchelvan, D. and Mondal, B. (2015) Bluetongue in India: A review. $A d v$. Anim. Vet. Sci., 5: 605-612.

10. OIE. Available from: http://www.oie.int/wahis_2/public/ wahid.php/Countryinformation/Reporting. Accessed on
20-05-2017.

11. Velthuis, A.G.J., Saatkamp, H.W., Mourits, M.C.M., de Koeijer, A.A. and Elbers, A.R.W. (2010) Financial consequences of the Dutch bluetongue serotype 8 epidemics of 2006 and 2007. Prev. Vet. Med., 93: 294-304.

12. Zientara, S., Sailleau, C., Viarouge, C., Höper, D., Beer, M., Jenckel, M., Bernd, H., Aurore, R., Labib, B.K., Aurore, F., Damien, V. and Emmanuel, B. (2014) Novel bluetongue virus in goats, Corsica, France, 2014. Emerg. Infect. Dis., 20(12): 2123-2125.

13. Bluetongue in the Russian Federation, Rosselkhoznadzor. (Electronic Resource) Available from: http://www.fsvps.ru/ fsvps-docs/ru/iac/2011/files/asf_2011-12-27.pdf. Accessed on 28-09-2016.

14. Bakulov, I.A., Knieze,A.V., Strizhakov, A.A., Dmitrenko, N.V. and Filomatova, V.A. (2007) Methodological recommendations on the management of epizootological monitoring of exotic especially dangerous and little known animal diseases. Raashn Gnu VNIIVVIM, Pokrov. p79.

15. OIE. (2014) Bluetongue, Manual of Diagnostic Tests and Vaccines for Terrestrial Animals, Part 2. Vol. 1. Ch. 2.1.3. OIE, Paris.

16. Ganter, M. (2016) Bluetongue disease-global overview and future risks. Small Rumin. Res., 118: 79-85.

17. Johnson, D.J. (2011) Identification of new United States bluetongue types. Proc. Am. Anim. Health A., 111: 209-210.

18. Kirkland, P.D. (2002) Bluetongue virus, vectors and surveillance in Australia-the current situation and unique features. Vet. Ital., 40(3): 47-50.

19. Rossi, S., Gibert, P., Bréard, E., Moinet, M., Hars, J., Maillard, D., Wanner, M., Klein, F., Mastain, O., Mathevet, P. and Bost, F. (2010) Circulation et impact des virus de la fièvre catarrhale ovine (FCO) chez les ruminants sauvages en France. Bull. Epidémiol., 35: 27-32.

20. Arenas-Montes, A.J., Arenas, A., García-Bocanegra, I., Mertens, P., Batten, C. and Nomikou, K. (2013) Serosurveillance of orbiviruses in wild cervids from Spain. Vet. Rec., 172: 508-509.

21. Bouchemla, F. and Agoltsov, V.A. (2015) Guidelines guide to diagnostics, prevention and control measures against the bluetongue. Vet. Dep. Saratov Region, 58: 33.

22. Casaubon, J., Chaignat, V., Vogt, H.R., Michel, A.O. and Thuer, B. (2013) Survey of bluetongue virus infection in free-ranging wild ruminants in Switzerland. BMC Vet. Res., 9: 166.

23. FAO Statistical Yearbook. Available from: http://www.fao. org/economic/ess/ess-publications/lannuaire-statistique/ fr/\#.WT0vmvnyjIU. Accessed on 01-02-2017.

24. Lorca-Oró, C., López-Olvera, J.R., Ruiz-Fons, F., Acevedo, P., García-Bocanegra, I., Oleaga, A., Gortázar, C. and Pujols, J. (2014) Long-term dynamics of bluetongue virus in wild ruminants: Relationship without breaks in livestock in Spain, 2006-2011. PLoS One, 8: e100027.

25. Miller, R.S., Farnsworth, M.L. and Malmberg, J.L. (2013) Diseases at the livestock-wildlife interface: Status, challenges, and opportunities in the United States. Prev. Vet. Med., 110: 119-132.

26. Pudupakam, R.S., Raghunath, S., Pudupakam, M. and Daggupati, S. (2017) Genetic characterization of the non-structural protein-3 gene of bluetongue virus serotype-2 isolate from India. Vet. World., 10(3): 348-352.

27. Ruiz-Fons, F., Sánchez-Matamoros, A., Gortázar, C. and Sánchez-Vizcaíno, J.M. (2014) The role of wildlife in bluetongue virus maintenance in Europe: Lessons learned after the natural infection in Spain. Virus Res., 182: 50-58.

28. Zientara, S. (2010) Historique des introductions successives de la FCO en Europe. Bull. Epidémiol., 35: 1-4. 